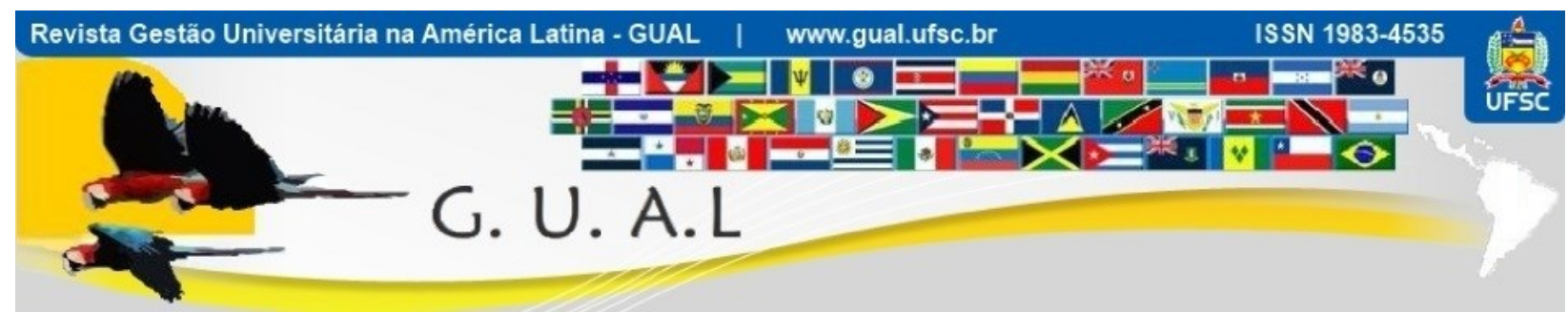

DOI: https://doi.org/10.5007/1983-4535.2021.e79120

\title{
IDENTIFICAÇÃO E DESEMPENHO ACADÊMICO: O OLHAR DOS ESTUDANTES
}

\section{IDENTIFICATION AND ACADEMIC ACHIEVEMENT: THE STUDENTS' VIEW}

\author{
Mara Danielly Mendonça Silva, Graduada \\ http://orcid.org/0000-0001-9303-4389 \\ mara.danielly04@gmail.com \\ Universidade Federal de Viçosa | Curso de Graduação em Administração \\ Viçosa | Minas Gerais | Brasil
}

Adriana Ventola Marra, Doutora https://orcid.org/0000-0003-3405-0308 aventola@ufv.br Universidade Federal de Viçosa | Campus Florestal Viçosa | Minas Gerais | Brasil

Nayara Kelly Ferreira dos Santos, Graduada http://orcid.org/0000-0002-0699-9391 nayarakellyfds@gmail.com Pontifícia Universidade Católica de Minas Gerais | Programa de Pós-graduação em Letras Belo Horizonte | Minas Gerais | Brasil

Recebido em 12/janeiro/2021

Aprovado em 16/junho/2021

Publicado em 01/setembro/2021

Sistema de Avaliação: Double Blind Review

Esta obra está sob uma Licença Creative Commons Atribuição-Uso. 


\title{
RESUMO
}

Este estudo teve como objetivo descrever as percepções dos discentes sobre as relações entre seu desempenho acadêmico e seu nível de identificação com o curso de graduação e com a instituição de ensino superior que estudam. O desempenho acadêmico do aluno é um dos fatores associados diretamente à evasão no ensino superior e pode estar associado a fatores sociais, demográficos e àqueles ligados à própria universidade, bem como a fatores psicológicos. Para tanto foi realizada uma pesquisa qualitativa descritiva, em que foram investigados os alunos do curso de graduação em administração da Universidade Federal de Viçosa (campus Florestal). Os dados foram coletados por observação participante, entrevistas semiestruturadas, técnica de escolha com 20 estudantes de diversos períodos. Foi realizada a análise de conteúdo e os dados organizados em três categorias: curso, universidade e desempenho acadêmico. Os resultados indicaram que a maioria dos discentes possui identificação ambivalente com o curso e se sentem superidentificados com a universidade, bem como se consideram com bom desempenho acadêmico. Concluiu-se que os alunos superidentificados tanto com o curso quanto com a universidade possuíam a tendência de ter um desempenho superior.

Palavras-chave: Desempenho Acadêmico. Identificação. Ensino Superior. Discente. Graduação em Administração.

\begin{abstract}
This paper aimed to describe the perceptions of students about the relationship between their academic achievement and their level of identification with the undergraduate course and with the higher education institution they study. The student's academic achievement is one of the factors directly associated with dropout in higher education and may be associated with social, demographic and those linked to the university itself, as well as psychological factors. For this purpose, a descriptive qualitative research was carried out, in which undergraduate students in administration from the Federal University of Viçosa (campus Florestal) were investigated. Data were collected through participant observation, semi-structured interviews, technique of choice with 20 students from different periods. Content analysis and data were organized into three categories: course, university and academic achievement. The results indicated that most students have ambivalent identification with the course and feel overidentified with the university, as well as considering themselves with good academic achievement. It was concluded that overidentified students with both the course and the university had a tendency to have a superior academic achievement.
\end{abstract}

Keywords: Academic Achievement. Identification. Higher Education. Student. Undergraduates in Administration. 


\section{INTRODUÇÃO}

A preocupação com o desempenho dos alunos de graduação é decorrente, dentre outros fatores, da baixa taxa de conclusão dos cursos, ou seja, da evasão que ocorre, principalmente, nas universidades federais. Segundo estatísticas gerais do Censo da Educação Superior (INEP, 2017), o número efetivo de concluintes nestas instituições chega a cerca de $11,50 \%$ dos ingressantes. Existem muitos modelos que explicam, de forma geral, os fatores que contribuem para a evasão no ensino superior, porém, cada aluno, curso e universidade apresentam suas peculiaridades no que se refere ao fenômeno. Contudo, a maioria dos estudos aponta alguns fatores comuns, que estão associados à universidade e aos discentes (OLIVEIRA et al., 2019). Os fatores que remetem à universidade como causa da evasão, dentre os principais, podem-se citar a qualificação do corpo docente e a infraestrutura da instituição (MIRANDA, 2011; MIRANDA et al., 2015; SANTOS, 2012). Quanto aos fatores associados ao aluno são apontados: características sociodemográficas dos discentes, desempenho acadêmico, problemas de saúde, ausência de apoio familiar, falta de comprometimento com a graduação, indefinição da escolha profissional, o tempo de matrícula no curso e a condição financeira dos estudantes (MIRANDA et al., 2015; OLIVEIRA et al., 2019; VITELLI, 2017).

Assim, tendo o desempenho acadêmico do aluno como um dos fatores associados diretamente à evasão no ensino superior, entende-se a relevância do estudo específico do tema. Pois, além de tal desempenho estar associado a fatores sociais, demográficos e àqueles ligados à própria universidade, como já mencionado, também há ligação com os fatores psicológicos do próprio estudante (HAVEROTH; SANTOS; CUNHA, 2019). Os autores apontam estes fatores como sendo: autoeficácia, autoestima, afeto, otimismo, lócus de controle, autocontrole e identificação com o curso. Haveroth, Santos e Cunha (2019) indicam a necessidade de aprofundamento dos estudos sobre tais fatores psicológicos associados ao desempenho acadêmico, pois, existem indicações de uma relação positiva entre o afeto e o desempenho dos discentes, ou seja, a tendência do desempenho acadêmico superior é fruto de uma elevada presença de afeto positivo. Diante da importância de estudar a evasão no ensino superior e de sua relação com o desempenho acadêmico, e da falta de estudos que associam os fatores psicológicos ao desempenho, este estudo buscou explorar a possível relação entre o processo de identificação - entendido como um vínculo afetivo - com o curso e com a universidade e o desempenho do estudante. 
A identificação pode ser compreendida como sendo um processo contínuo entre o eu e o outro, no qual os indivíduos ou os grupos se encontrariam potencialmente em momentos de inteira concordância, compartilhando seus valores e crenças, e criando vínculos afetivos (ALBERT; ASHFORTH; DUTTON, 2000; FREITAS, 2000). As identidades são construídas pelos indivíduos ao longo da vida, por meio de seus processos de identificação, que se dão a partir de semelhanças e diferenças (JENKINS, 2008). Assim, neste estudo, entende-se o eu (indivíduo) - estudante de graduação - neste processo contínuo de analisar suas semelhanças e diferenças com os outros - o curso de graduação e a própria universidade que estuda.

Diante do contexto apresentado, este estudo teve como objetivo descrever as percepções dos discentre sobre as relações entre seu desempenho acadêmico e seu nível de identificação com o curso de graduação e com a instituição de ensino superior que estudam. $\mathrm{O}$ estudo de campo foi conduzido com os alunos do curso de administração da Universidade Federal de Viçosa/Campus Florestal (UFV/CAF). Em março/2020, o curso de administração, neste campus, contava com 283 alunos matriculados e uma taxa de evasão de 39,8\% (UFV, 2020).

Em busca realizada em maio de 2020 na base de dados da Scielo (Scientific Electronic Library Online) e da SPELL (Scientific Periodicals Eletronic Library), com o cruzamento dos seguintes termos: "identificação", “discente”, “instituição de ensino superior” e "universidade", não foi obtido nenhum resultado em relação aos artigos nacionais publicados na área do curso de Administração. Em relação ao levantamento de dados sobre o termo "desempenho acadêmico", foram encontrados na SPELL 37 artigos, dos quais seis eram específicos do curso de Administração, 22 de Ciências Contábeis e os outros nove abordavam outros cursos ou tratavam da universidade como um todo. Contudo, nenhum deles aborda de maneira específica os fatores psicológicos e, em especial a identificação, como associados ao desempenho acadêmico.

Diante do exposto, nota-se a relevância deste estudo ao buscar compreender se a identificação com o curso e com a instituição é percebida, pelos estudantes de graduação, como provável influenciador para o desempenho acadêmico. Além disso, o estudo também poderá contribuir com os atores envolvidos no processo de ensino e aprendizagem da área de administração, auxiliando diretores, coordenadores e docentes no planejamento de estratégias pedagógicas mais adequadas às necessidades dos estudantes. 


\section{REFERENCIAL TEÓRICO}

\subsection{FATORES DETERMINANTES DO DESEMPENHO ACADÊMICO}

O desempenho acadêmico tem sido um dos indicadores mais investigados quando se busca compreender as causas do fracasso ou do sucesso escolar, sendo a evasão um dos sinalizadores do fracasso (BRANDT; TEJEDO-ROMERO; ARAUJO, 2020). Tal preocupação com o desempenho acadêmico justifica-se, entre outras razões, pelo fato de que quando é positivo, o desempenho está associado a menor estresse, a um autoconceito positivo, a maior autoeficácia, a um comportamento saudável e ao aumento do bem-estar subjetivo (BÜCKER et al., 2018).

Contudo, um dos desafios para analisar o desempenho acadêmico é definir a forma de mensurá-lo. Munhoz (2004, p. 37) afirma que "a descrição do termo desempenho envolve a dimensão da ação, e o rendimento é o resultado da sua avaliação, expresso na forma de notas ou conceitos obtidos pelo sujeito em determinada atividade". Diante disso, o autor considera o desempenho acadêmico como um ato de observar o indivíduo ou o grupo perante a execução das tarefas acadêmicas, avaliando-os através da eficiência e rendimento. Essa avaliação busca indicar o nível de aptidão do indivíduo e seus resultados obtidos devem ser analisados a fim de melhorias contínuas para todos os envolvidos no processo (MUNHOZ, 2004). Conforme Lopes et al. (2010, p. 2), “[...] a avaliação do desempenho tem como objetivo acompanhar o processo de aprendizagem dos acadêmicos em relação ao conteúdo programático previsto na grade curricular do curso". O ponto em comum de tais definições está no desempenho do discente sofrer influência de diversos fatores, sendo difícil ser estabelecida uma medida exata (LOPES et al., 2010; MUNHOZ, 2004).

Os fatores que podem influenciar o desempenho são múltiplos. Miranda et al. (2015) e Corbucci (2007) sumarizam, a partir de uma revisão da literatura sobre os determinantes do desempenho acadêmico na área de negócios, que tais fatores estão relacionados a três grupos: ao corpo docente, às instituições de ensino e ao corpo discente. No que diz respeito às categorias de instituição e corpo docente, há crenças de que a maior titulação dos professores e melhores infraestruturas institucionais exercem condições positivas para qualidade do ensino (MOREIRA, 2010). Quanto ao corpo discente, considera-se que as características individuais e socioeconômicas em que se encontram e os fatores acadêmicos influenciam no desempenho acadêmico dos estudantes (CORBUCCI, 2007; MOREIRA, 2010). Tais características incluem as socioeconômicas e culturais dos estudantes e de suas famílias 
(renda familiar, escolaridade e profissão dos pais, por exemplo), bem como etnia (em função das desigualdades sociais), gênero e idade (BRANDT; TEJEDO-ROMERO; ARAUJO, 2020). Como fatores acadêmicos, compreende-se, dentre outros, o número de horas dedicadas aos estudos, a existência de suporte financeiro, o tempo despendido com o trabalho (DURÁN SANTOMIL et al., 2016).

Além dos fatores institucionais, discentes e docentes, estudos indicam que o desempenho acadêmico também está associado a fatores psicológicos do estudante (HAVEROTH; SANTOS; CUNHA, 2019). Um estudo recente levanta que um dos fatores psicológicos que pode influenciar no desempenho acadêmico é a motivação. Muitos alunos são motivados de maneira equivocada, em que se preocupam apenas com notas, diplomas e ameaças de reprovação, e não com o aprendizado em si (CRESTANI, 2015).

Borges, Miranda e Freitas (2017) também afirmam que existe uma relação entre motivação e desempenho acadêmico do aluno. Contudo, tal relação depende do tipo de motivação que o discente possui. Para os autores, a motivação do aluno pode ser intrínseca ou extrínseca. Em uma pesquisa com os estudantes do curso de Ciências Contábeis de uma universidade pública, os autores perceberam que os alunos com maiores níveis de motivação extrínseca apresentavam menores níveis de desempenho acadêmico do que aqueles com a motivação intrínseca.

Outro fator é o autocontrole. Duckworth et al. (2019, p. 373) definem autocontrole como o "alinhamento de pensamentos, sentimentos e ações com os objetivos valorizados de forma duradoura em face às alternativas mais atraentes". Segundo os autores, a maioria dos estudantes experimenta ao longo da vida conflitos entre suas metas acadêmicas a longo prazo e as metas não acadêmicas, que consideram mais gratificantes, a curto prazo. Evidências indicam que o autocontrole envolve desenvolver estratégias para enfraquecer os impulsos que desviam o estudante de suas metas acadêmicas. Assim, o autocontrole é preditor do desempenho acadêmico em todos os níveis de ensino (DUCKWORTH et al, 2019)

Haveroth, Santos e Cunha (2019) também revelam em seu estudo que os afetos positivos mais influentes durante o curso de Ciências Contábeis se resumem em: interessado(a), determinado(a) e atento(a), e os negativos se resumem em: aflito(a), nervoso(a) e tenso(a). Dessa forma,o estudo evidencia a relação existente entre o afeto e o desempenho dos discentes de Ciências Contábeis, demonstrando que uma maior presença de afeto positivo acarreta em uma tendência maior do desempenho acadêmico ser melhor. 


\subsection{PROCESSO DE IDENTIFICAÇÃO}

O processo de identificação é o principal mecanismo que os indivíduos utilizam para se diferenciarem uns dos outros, analisando sistematicamente suas semelhanças e divergências no que se refere aos demais, sejam pessoas, grupos, objetos ou instituições (JENKINS, 2008). Segundo Ashforth, Harisson e Corley (2008), o processo de identificação é uma interação entre indivíduos e grupos, em que os indivíduos começam a incorporar elementos do coletivo em seu ser.

Kreiner e Ashfort (2004) alegam que o sujeito, a partir da identificação, busca construir um entendimento de pertencimento a um grupo humano, tentando entender quem ele é. Por meio desse processo o indivíduo se percebe como membro, absorvendo, assim, atributos do coletivo para si, o que permite afetar diretamente o seu comportamento e atitudes. Esse juízo de pertencimento está profundamente ligado ao entendimento dos limites do grupo, da diferenciação e da distintividade. Os autores entendem que a compreensão de fronteiras pode aguçar o grupo a tornar-se mais similar para distinguir-se dos grupos externos e se autoproteger. Desta forma, Kreiner e Ashforth (2004) apresentam um modelo expandido de identificação, demonstrando como ocorre esse processo e também apontam que a identificação pode ocorrer de quatro formas: a) identificação neutra; b) superidentificação; c) desidentificação e d) identificação ambivalente (Figura1).

Figura 1 Modelo Expandido de Identificação

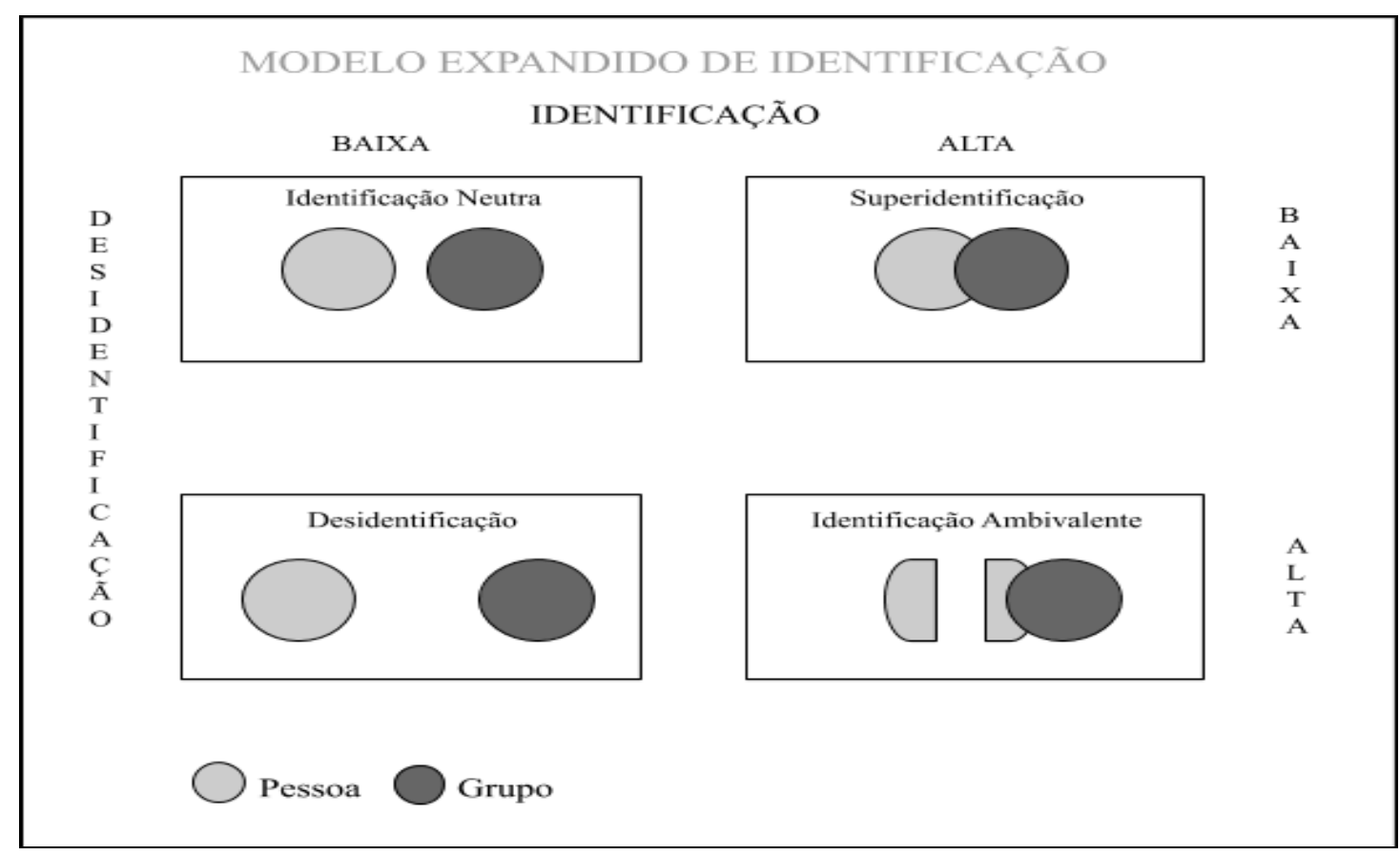

Fonte: Adaptada de Kreiner e Ashforth (2004, p. 6). 
A primeira situação refere-se à Identificação Neutra, em que o indivíduo não se identifica e nem se desidentifica com a instituição em questão. O sujeito apresenta ausências de percepções e apegos ou até mesmo evitam algum tipo de vínculo (KREINER; ASHFORTH, 2004). A segunda ocorrência diz respeito à superidentificação, na qual o sujeito tem uma ligação afetiva muito forte com a instituição (ASHFORTH et al., 2013; KREINER; ASHFORTH, 2004). Já a desidentificação pode ser entendida como ser diferente do grupo, o indivíduo, de forma clara ou subconsciente, acaba separando sua identidade individual da identidade do grupo (ASHFORTH et al., 2013; KREINER; ASHFORTH, 2004). Por fim, temos o último se refere à identificação ambivalente, em que o indivíduo, de forma simultânea, se identifica e desidentifica com a instituição ou com aspectos dela (KREINER; ASHFORTH, 2004).

Em conformidade com o que foi exposto sobre identificação, Ogushi e Bardagi (2015), nos revelam que a vivência em uma instituição universitária sofre com constantes modificações do posicionamento do estudante frente ao seu processo de escolha. Assim, quando a instituição de ensino superior consegue comunicar seus valores para a sociedade, impacta de maneira positiva no orgulho de pertencimento dos indivíduos, contribuindo, dessa forma, para a construção da identificação e pertencimento por parte dos sujeitos envolvidos (SCHARF, 2016).

Autores como Boros e Curseu (2012) revelam ainda que quanto maior for o prestígio da universidade no ambiente externo, mais identificados serão os discentes com a instituição. O estudo aponta também que, quando os discentes não se identificam com sua instituição de ensino, esses agirão contra os valores e normas estabelecidas, desenvolvendo atitudes que os distanciem da instituição. Em síntese, para Scharf (2016), o modo como o indivíduo se sente dentro de determinada instituição, os esforços despendidos para dizer que pertence a ela e, ainda, a crença de que o sucesso da universidade tem uma relação direta com o seu próprio sucesso, evidenciam sua identificação com a instituição

\section{METODOLOGIA}

Com o intuito de compreender e analisar a questão de pesquisa, foi realizado um estudo de natureza qualitativa com caráter descritivo. Segundo Creswell (2007), a pesquisa qualitativa se desenvolve em um ambiente natural, no qual o pesquisador vai até o local em que o participante se encontra para coletar os dados, possibilitando, assim, observar detalhes sobre o pesquisado ou sobre o local. É descritivo, visto que permitiu o levantamento e a 
formação de bases de dados sobre um fenômeno social definido, que poderão contribuir para trabalhos futuros de caráter comparativo e formulação de teoria (GIL,2008).

Como foram utilizadas diversas fontes para coleta de dados - observação participante, entrevistas semiestruturadas, técnica de escolha -, configura-se em uma triangulação de dados. Para Yin (2001), a triangulação é um fundamento lógico que permite utilizar várias fontes de evidências, com diferentes perspectivas teóricas e diferentes momentos no tempo, consolidando-se, dessa maneira, as conclusões que dizem respeito ao fenômeno investigado. Por meio da observação participante, cujas anotações realizadas foram feitas no diário de campo, foi possível juntar dados que consistiram nas observações durante as entrevistas e/ou após o desligamento do gravador, além de ser observado o comportamento dos discentes de Administração na Universidade Federal de Viçosa/Campus Florestal (UFV/CAF).

De acordo com Godoi e Mattos (2006), a entrevista semiestruturada tem a presença de perguntas parcialmente formuladas, ou seja, permite o aprofundamento de elementos que podem aparecer durante a entrevista. O número de indivíduos entrevistados foi delimitado por saturação de dados, ou seja, quando novos dados na pesquisa foram relevantes e nem agregaram esclarecimentos para a investigação, visto que todos os temas, conceitos e teorias relevantes para a pesquisa já foram considerados (CRESWELL, 2007). Dessa forma, foram entrevistados 20 discentes entre dezembro de 2019 e março de 2020.

Ademais, o critério de seleção desses 20 entrevistados se deu por acessibilidade e estratificação, sendo excluídos os ingressantes no ano de 2020, por ainda terem pouco contato com o curso e com a universidade. De acordo com Godoi e Mattos (2006), o ato de selecionar participantes por acessibilidade permite maior amplitude para o pesquisador, uma vez que ele poderá exercer a escolha dentro de um campo de entrevistados conforme o alcance e disponibilidade compatíveis. Também foi utilizado o critério de estratificação para selecionar o mesmo número de alunos de acordo com o ano de ingresso na UFV/CAF, sendo 5 alunos para cada ano de ingresso. O perfil dos participantes da pesquisa pode ser resumido como a maioria possui entre 18 e 20 anos (55\%), é mulher (55\%) e reside fora do município de localização do campus (75\%), como podemos ver na tabela 1 . Todos os participantes foram codificados de E1 a E20 para preservar seu anonimato.

A técnica de escolha teve inspiração projetiva (DONOGHUE, 2000), na qual os entrevistados selecionaram os estímulos de uma lista com quatro figuras referentes ao modelo expandido de identificação (KREINER; ASHFORTH, 2004) e escolheram a categoria que melhor os representava em relação ao curso de administração e à UFV. 
Tabela 1 Perfil dos participantes

\begin{tabular}{|c|c|c|}
\hline Dados demográficos & Frequência absoluta & Freqüência relativa \\
\hline \multicolumn{3}{|l|}{ Idade } \\
\hline $18-20$ anos & 11 & $55 \%$ \\
\hline $21-23$ anos & 4 & $20 \%$ \\
\hline $24-26$ anos & 4 & $20 \%$ \\
\hline Acima de 27 anos & 1 & $5 \%$ \\
\hline \multicolumn{3}{|l|}{ Sexo } \\
\hline Masculino & 9 & $45 \%$ \\
\hline Feminino & 11 & $55 \%$ \\
\hline \multicolumn{3}{|l|}{ Localidade da residência } \\
\hline Betim & 5 & $25 \%$ \\
\hline Contagem & 8 & $40 \%$ \\
\hline Florestal & 5 & $25 \%$ \\
\hline Pará de Minas & 2 & $10 \%$ \\
\hline \multicolumn{3}{|l|}{ Previsão de formatura } \\
\hline 2020 & 3 & $15 \%$ \\
\hline 2021 & 5 & $25 \%$ \\
\hline 2022 & 7 & $35 \%$ \\
\hline 2023 & 4 & $20 \%$ \\
\hline 2024 & 1 & $5 \%$ \\
\hline
\end{tabular}

Fonte: dados de pesquisa.

Os dados foram analisados por análise de conteúdo (BARDIN, 2011). Primeiramente foi realizada uma pré-análise, em que foram sistematizadas as ideias iniciais. Posteriormente, o material foi explorado e foram formuladas as categorias de análise, a partir das unidades de registro. Por fim, foi realizado o tratamento, a inferência e a interpretação dos dados, demonstrando, assim, todos os conteúdos manifestados através do material coletado, salientando todos os tópicos elencados como semelhantes e diferentes. As categorias finais trabalhadas foram estabelecidas a priori pelo referencial teórico: curso, universidade e desempenho acadêmico.

\section{ANÁLISE E DISCUSSÃO DOS RESULTADOS}

\subsection{CURSO}

A fim de melhor compreender a percepção dos participantes sobre seu próprio desempenho acadêmico e os possíveis fatores determinantes, buscou-se entender como foi o caminho perpassado pelos entrevistados até o ingresso no curso. Ao investigarmos a trajetória escolar dos participantes no ensino fundamental e médio a maioria afirmou ser dedicado e bom aluno, apresentando bom desempenho. Entender esse trajeto pode ser de suma 
importância para o desempenho acadêmico do aluno, conforme abordado nos estudos de Corbucci (2007), Miranda et al. (2015) e Moreira (2010).

Os principais motivos para a escolha do curso de Administração foram: administração como segunda opção (10); nota de corte (8); a experiência e vivência no mercado de trabalho ligado à área administrativa (5); questões financeiras (3); a influência da família (3); dúvidas sobre o curso (2) e a vontade de ter o próprio negócio (1).

Bom, na verdade Administração era minha segunda opção de curso, minha primeira opção era Arquitetura, ainda é até hoje, é, só que como eu consegui passar primeiro em Administração eu inverti a ordem, primeiro fiz Administração e agora pretendo fazer Arquitetura. (E2)

Eu já fiz um curso técnico de Contabilidade, então eu já gostava dessa área de processo, tanto é que eu já trabalhei na área de assistente, auxiliar administrativo, então foi o que me fez escolher essa faculdade, esse curso. (E9)

Como podemos ver nos relatos de E2 e E9, há discentes que apresentam incertezas, ou que por algum motivo optaram pelo curso por falta de outra oportunidade no momento. Contudo, também existem discentes que escolheram o curso de Administração por manifestar predileção pela área e almejar algum crescimento dentro dela. Dessa forma, por mais que muitos tenham optado por este curso por não terem outra opção, muitos também fizeram a escolha por saberem o que queriam e quais portas que o curso poderia abrir, como a possibilidade de ter o próprio negócio.

Antes de ingressarem no curso a maioria dos entrevistados esperava aprofundar nas matérias, ter aulas práticas e ter que estudar muito. Contudo, após o ingresso no curso de administração, os discentes perceberam uma quebra de expectativa causando insatisfação com o conteúdo introdutório do curso, apontando era muito teórico; amplo e genérico e que tinham a sensação que não estavam aprendendo, como apontam E3 e E10.

O primeiro ano eu senti que eu não estava ainda entendendo muito bem sobre o curso. As matérias eram muito básicas, era algo muito geral, então eu tinha uma expectativa de que o segundo ano seria mais interessante que eu iria ver mais coisas sobre o curso mesmo. (E3)

Então, eu achei o curso muito teórico, acho que tá faltando prática, tá muito focado só em teoria. (E10)

Pode-se observar que um número significativo de participantes que no início da entrevista relataram ter escolhido o curso como segunda opção enxergam, no atual momento do curso, pontos positivos com os quais se identificam. Tais pontos estão a amplitude de 
atuação em diversos setores que o curso de administração pode lhes oferecer, como apontado no depoimento de E15 que afirma: "é uma área muito ampla, poderia fazer muitas coisas e quem sabe dentro da administração eu poderia descobrir alguma coisa que eu gosto" (E15).

Por fim, para que os discentes relatassem sua identificação com o curso foi utilizada a técnica de escolha de inspiração projetiva, em que apresentamos quatro figuras, representando o individuo e o curso de administração, a partir do modelo expandido de identificação de Kreiner e Ashforth (2004). Dessa forma, os discentes responderam a maneira com a qual se viam em relação ao curso, ou seja, com identificação neutra; desidentificação; superidentificação e identificação ambivalente (Quadro 1).

Quadro 1 Identificação dos discentes em relação ao curso de Administração da UFV/CAF

\begin{tabular}{|c|c|c|}
\hline $\begin{array}{c}\text { Tipos de } \\
\text { Identificação }\end{array}$ & Figuras & Entrevistados \\
\hline Neutra & & E10; E11; E12; E13 \\
\hline Desidentificação & \\
\hline Superidentificação & \\
\hline Ambivalente & \\
\hline
\end{tabular}

Fonte: dados da pesquisa.

Dentro do aspecto de identificação com o curso, as relações entre os tipos de identificação e as justificativas para essa escolha se complementam. A maioria dos participantes possui uma identificação ambivalente com o curso, ou seja, apresentam sentimentos contraditórios de concordarem e discordarem de algumas questões, como está exemplificado no depoimento de E4. Um dos pontos discordantes é considerarem o curso muito teórico como apontado anteriormente

Porque penso que a faculdade agrega muito conhecimento, mas é como eu disse, é muito diferente do mercado de trabalho, então ao mesmo tempo que eu estou me identificando diretamente com a faculdade, ao mesmo tempo quando eu olho pra fora eu vejo que o que eu aprendi aqui não é tão relevante. (E4)

Ademais, um tipo que se destacou ao longo da pesquisa refere-se à Superidentificação, visto que os três entrevistados que se veem com essa relação com o curso, antes consideravam-o como uma segunda opção ou se interessavam somente pela nota de corte, e 
hoje conseguiram se conectar de uma forma tão profunda, que se veem de maneira superidentificada. Dois destes discentes estão perto da conclusão do curso, o que pode indicar que ao longo dos anos, os discentes passam a incorporar elementos do coletivo em seu ser e se sentirem mais identificados. Pois, conforme o apontado por Ashforth, Harisson e Corley (2008), o processo de identificação se configura pela interação entre indivíduos e grupos.

Eu gosto muito do curso, eu fiquei até um pouco surpreendida, eu vejo que eu tenho muitas características que tem a ver com esse curso de Administração. [...] eu realmente acredito que esse curso tem muito a ver comigo. (E3)

Um dos se considera desidentificado. A desidentificação acontece quando o indivíduo se percebe diferente do grupo e não quer ver sua identidade ligada ao grupo. Neste caso, E17 justifica seu próprio desconhecimento sobre a matriz curricular do curso e, por isso, suas expectativas serem distoantes da realidade.

Bom eu acho que esperava uma coisa diferente eu já tinha assim, sabia o nome de algumas matérias ou outra, mas ali na prática eu esperava que era algo diferente, aí acabou que algumas matérias é meio que umas coisas que você já viu na escola, pelo menos no início então, mas eu acho que essa expectativa errada foi mais um erro meu e não do que realmente é. (E17)

Durante o processo de observação também pode-se perceber que que muitos alunos carregam consigo algo que retrata o nome do curso de Administração (copo, caneca, caneta, camiseta, por exemplo). Contudo, o simbolismo representado pelo objeto nem sempre significa uma superidentificação com o curso, principalmente considerando que a maioria dos participantes (16) se percebem identificados de forma ambivalente ou neutra.

Muitos alunos, de todos os cursos e principalmente Administração usam alguma peça de roupa ou caneca com o nome do curso e com o nome da UFV. Será que essas pessoas que carregam consigo o nome do curso são identificados?! (Trecho do diário de campo -09/10/2019).

Vale lembrar que, de acordo com Kreiner e Ashforth (2004), o indivíduo pode se identificar e desidentificar simultaneamente com os aspectos do meio em que está inserido, então, nesse caso, o fato dos alunos carregarem consigo o nome do curso e da universidade pode retratar, por exemplo, o orgulho de pertencimento à marca UFV/CAF, mas não ao curso de Administração. Portanto, com base na Identificação Ambivalente e no discorrido anteriormente, é possível os discentes se identificarem com alguns aspectos como a marca da UFV e retratarem isso em forma de objetos e roupas. 


\subsection{UNIVERSIDADE}

A fim de proporcionar uma melhor compreensão da percepção dos discentes sobre a UFV/CAF, foi abordado o que eles consideram como principais atrativos da universidade. Os mais citados foram: localização do campus próxima da residência, o reconhecimento da UFV na sociedade, o clima da faculdade, o fato de ser pública e ter bons professores. Dentre esses atrativos mencionados, o de reconhecimento da UFV vai ao encontro do que Scharf (2016) revela sobre o orgulho de pertencimento do indivíduo. O depoimento de E8 e E12 ilustram tais atrativos.

Bom, em relação a universidade é que fica perto de $\mathrm{BH}$, eu não queria morar longe [...] Ah eu acho que o que me deixa mais feliz em tá lá dentro é o reconhecimento, igual ser destaque em alguns cursos e tudo mais. (E8)

Ah eu fiquei encantada quando eu fui lá pela primeira vez, encantada, tipo assim nossa é um ambiente completamente diferente do que eu já tinha conhecido de faculdade de universidade, [...]... O que mais me atrai é o clima, o ambiente. (E12)

Outro aspecto analisado foi sobre os sentimentos despertados pelos discentes dentro da UFV/CAF. Como resultado, dado por meio da observação feita e dos depoimentos recolhidos que demonstram o ponto de vista dos participantes, mostrou-se que os sentimentos que são considerados positivos foram mais fortes que os negativos. A maioria dos entrevistados relatou que se sente bem e feliz dentro do ambiente da universidade e, além disso, um aspecto digno de atenção é o fato de que a segunda maior resposta dada pelos discentes faz referência a sentir-se acolhido pela UFV/CAF. Os depoimentos de E11 e E5 exemplificam esta relação: "Ah, eu me sinto acolhido, por ser de longe eu me sinto muito bem". (E11) e "me sinto em casa [...] é essa a palavra mesmo, em casa”. (E5)

A percepção de acolhimento pelo grupo é um dos principais fatores que influenciam positivamente a identificação como afirmam Albert, Ashforth e Dutton (2000). Tal acolhimento do grupo é reflexo da proximidade com os professores e do clima da universidade. Como afirma E19: "a relação com a maioria dos professores, nós temos muito acesso a eles, então é uma coisa que facilita bastante, você consegue desenvolver mais, tirar dúvidas ou coisa do tipo.” (E19)

Utilizando a mesma técnica de escolha com as figuras do modelo expandido de identificação de Kreiner e Ashforth (2004), foi questionado aos entrevistados como eles se percebem em relação a UFV/CAF. Conforme observado no quadro 2, os tipos de identificação 
em relação à universidade, mais apontados pelos discentes, foram a Neutra e a Superidentificação.

Quadro 2 Identificação dos discentes em relação a Universidade UFV/CAF

\begin{tabular}{|c|c|c|}
\hline $\begin{array}{c}\text { Tipos de } \\
\text { Identificação }\end{array}$ & Representação gráfica & Entrevistados \\
\hline Neutra & & E1; E4; E7; E13; E15; E16; E17; E18 \\
\hline Desidentificação & \\
\hline Superidentificação & & E10 \\
\hline Ambivalente & \\
\hline
\end{tabular}

Fonte: dados de pesquisa.

Os alunos que se enquadram como superidentificados com a UFV/CAF podem se sentir dessa forma devido ao orgulho de pertencimento à marca, o que os leva a demonstrar por meio de uso de objetos e roupas com nome da universidade, conforme observado, ou pelo próprio fator do acolhimento, como relata E2.

A UFV eu considero que eu tenho uma Superidentificação porque eu sempre gostei em toda minha vida acadêmica assim, eu sempre gostei muito de ter envolvimento com professor, [...] então com a UFV eu me identifiquei muito por isso, aqui a gente tem muita aproximação com o professor, a gente tem muita chance. (E2)

Por sua vez, muitos dos discentes que se enquadraram em uma Identificação Neutra não apresentam vínculos com a universidade em si, ou que não foi desenvolvido nenhuma forma de vínculo com a instituição de ensino, o que significa que podem ser considerados imparciais em relação aos valores pregados pela instituição, conforme aponta Ashforth (2013). Como afirma E1, pelo fato do curso ser noturno, ele "não frequenta quase lugar nenhum, só a pavilhão de aula e a lanchonete, e de vez enquanto a biblioteca,só".

Se compararmos as percepções de identificação com a universidade (Quadro 2) com às do curso (Quadro 1), os alunos que se viram neutros com a universidade também se identificaram como neutros, ou como ambivalentes, ao curso de Administração. Em contrapartida, os discentes que se colocaram como superidentificados com a universidade, em algum momento da graduação, desenvolveram um vínculo muito forte coma instituição. Ademais, é importante ressaltar que os entrevistados que se colocaram como 
superidentificados com a UFV/CAF antes, quando indagados em relação à identificação em relação ao curso de Administração, se colocaram em situação de identificação neutra e ambivalente, sendo que apenas o E5 se viu superidentificado em ambos os cenários.

\subsection{DESEMPENHO ACADÊMICO}

Para dar início à categoria de desempenho acadêmico, faz-se necessário entender um pouco mais sobre o rendimento de cada discente participante. Durante a entrevista, foi solicitado aos participantes que falassem sobre os seus Coeficientes de Rendimento Acadêmico (CRA). A maioria dos participantes (12) possui CRA entre 60,1 e 80; cinco acima de 80 e três abaixo de 60. Ao fazer o cruzamento de tais dados com os motivos da escolha do curso percebe-se que sete dos que possuem CRA entre 60,1 até 80 escolheram o curso como segunda opção (E1; E5; E6; E11; E12; E15 e E18). No entanto, por mais que o curso tenha sido escolhido por muitos dessa forma, a maioria se identificou e dedicou ao longo do curso.Tal dedicação e desempenho acadêmico satisfatório pode estar ligada ao autocontrole e a motivação intrinseca, corroborando os achados de Duckworth et al. (2019) e de Borges, Miranda e Freitas (2017). Sobre o autocontrole e a motivação intrínseca E20 apresenta seu depoimento reafirmando a importância de desenvolver estratégias para focar em suas metas acadêmicas e frequentar a universidade pelo conhecimento.

Então, agora eu pretendo nas próximas disciplinas ter um contato maior com a administração, que seja realmente disciplinas que vão me agregar que eu possa tirar algum proveito, e não apenas está lá por hora, por obrigação, e sim pra receber algum conhecimento. (E20)

De acordo com as notas pontuadas por cada participante, foi abordado, em seguida, a respeito da percepção de cada discente em relação a esse rendimento, ou seja, sobre o seu próprio desempenho. As respostas pautadas foram: desempenho bom (10); desempenho

mediano (7) e desempenho ruim (3). Logo, pode-se concluir que cada discente tem a sua percepção sobre o seu desempenho, sua própria realidade e isso pode depender da influência de vários fatores, como: padrão de comparação com pessoas próximas, como eram antes na escola e a autocobrança, porém, é difícil estabelecer uma medida exata, conforme apontam Lopes et al. (2010) e Munhoz (2004). A seguir, alguns relatos para melhor compreensão do motivo pelo qual os entrevistados se veem dessa forma. 
Analisando o contexto eu acredito que meu desempenho foi bom, considerando meu coeficiente, minhas notas, minha participação nas aulas, eu acredito que foi bom. (E3)

Tá razoável, não me dedico tanto então não tenho as notas tão boas, mas tá razoável. (E18)

Conforme os relatos expostos acima, o próprio desempenho acadêmico dos alunos no curso superior está associado a fatores sociais, demográficos e à própria universidade, bem como a fatores psicológicos do próprio estudante (HAVEROTH; SANTOS; CUNHA, 2019). Sendo assim, faz-se necessário abordar sobre as dificuldades encontradas pelos discentes ao longo do percurso acadêmico. Os participantes enfrentaram diversas adversidades ao longo do curso, dentre as quais as mais citadas foram: dificuldade em algum período; dificuldade em alguma matéria específica; falta de dedicação ou de tempo; falta de didática de professor; o fato de ser uma experiência nova; dificuldade por questões pessoais e deixar acumular algumas matérias. Com isso, pode-se perceber que as dificuldades mais apontadas estão voltadas para questões do corpo discente, fazendo referência às falhas dos alunos que podem estar relacionadas a diversas variáveis, como aponta Miranda et al. (2015), e não diretamente à instituição e ao corpodocente.

No que tange aos fatores que ajudam no desempenho do aluno, foi citado o apoio familiar pela maioria dos participantes. Tal fato é corroborado com Miranda et al. (2015) que afirmam que a base familiar é de suma importância para o desempenho acadêmico. Por sua vez, os participantes apontaram como fatos que atrapalham seu desempenho: a distância da faculdade; a desmotivação; a falta de autocontrole e o hábito de mexerem nos celulares durante as aulas. Como afirma E14, o fato de não conseguir focar nas suas metas acadêmicas de longo prazo, priorizando sua vida social a curto prazo, atrapalham seu desempenho, corroborando com as indicações de Duckworth et al. (2019).

Minha vida social me atrapalha, porque eu acabo viajando muito [...], e acho que mais minha vida social e eu também não gosto de ficar muito, de ficar estudando muito, por muito tempo. (E14)

No que se refere à distância do campus, os discentes levantaram essa questão devido ao fato de que o tempo de deslocamento gasto todos os dias poderia ser utilizado para estudo, se a faculdade apresentasse uma localização mais favorável.

Como objetivo de verificar a possível relação entre o desempenho e a identificação com o curso e com a universidade, os entrevistados foram questionados se caso estudassem 
em outra universidade ou se fizessem outro curso superior,teriam um melhor desempenho. A maioria (14) afirmou que não teriam desempenho melhor em outra universidade e/ou outro curso. Dos seis que afirmaram que teriam melhor desempenho, as justificativas foram se a universidade fosse mais fraca, os professores melhores e se pagassem, iriam se dedicar. Dessa forma, excluindo-se a questão de melhores professores e do nível de exigência, pode-se inferir que, na percepção dos alunos, o desempenho não está ligado à universidade em si ou ao próprio curso. Assim, pode-se inferir que, na percepção dos participantes, os motivos de um melhor desempenho estariam mais ligados ao próprio discente em si.

Retomando o tema discutido no início desta análise, sobre o caminho da escolha do curso, nota-se que mesmo os que apresentavam dúvidas sobre o curso antes de iniciar a graduação, atualmente afirmam que o curso é o que realmente querem e que não teriam um desempenho melhor em algum outro curso.

Acredito que não, porque eu tenho certeza da escolha que eu fiz, então é administração que eu quero e eu estou na universidade onde eu gostaria de fato estar. (E6)

No geral, sumarizando os principais pontos levantados através das análises feitas neste estudo, o trabalho apontou que existe uma possível relação entre identificação e desempenho acadêmico. Nesta pesquisa, esta relação se apresentou mais forte em relação à instituição de ensino, pois os discentes se mostraram mais apegados afetivamente à UFV/CAF, do que ao curso de Administração em si. Ainda sobre o desempenho acadêmico dos alunos, pode ser pautado que a maioria permaneceu no mesmo patamar de como eram no ensino fundamental e médio. Não sendo necessariamente o curso ou a universidade que influenciam no seu desempenho.

\section{CONSIDERAÇÕES FINAIS}

O objetivo deste trabalho foi descrever as percepções dos discentes acerca das relações entre seu desempenho acadêmico e seu nível de identificação com o curso de Administração e com a UFV/CAF. A partir das análises dos dados, pode-se perceber que há indicações de uma possível relação entre identificação e desempenho acadêmico.

Frente aos métodos de análises adotados neste trabalho, foi possível observar, de uma forma geral, que a maioria dos discentes relatou que possui um nível de Identificação Ambivalente, ou seja, concorda com alguns aspectos do curso de Administração, mas discorda com outros; ou Neutra em relação ao curso de Administração, em que se apresenta 
como imparcial em relação aos valores pregados no curso. Assim, conclui-se que poucos discentes se sentem superidentificados com o curso.

No que tange à identificação dos discentes com a UFV/CAF, a maioria dos alunos entrevistados apontou uma Superidentificação com a universidade. Assim, pode-se concluir, de uma forma geral, que estes têm uma relação mais próxima com a instituição de ensino do que com o próprio curso, sendo os principais fatores que contribuem para esta Superidentificação: ambiente de acolhimento e clima proporcionado pela universidade.

A respeito do desempenho acadêmico dos discentes, pode-se concluir que a maioria dos entrevistados apresentou um Coeficiente de Rendimento Acadêmico que consideraram como bom e, fazendo uma associação entre a identificação com a universidade e o desempenho, percebeu-se que os alunos com uma Superidentificação possuíam a tendência de ter um bom desempenho. Percebeu-se também a imagem de prestígio construída pela UFV gerando um orgulho de pertencimento muito grande nos discentes, quanto o fato de serem alunos de uma universidade federal.

Sendo assim, faz-se necessário abordar sobre a relevância desta pesquisa para o meio acadêmico e para a instituição na qual foi realizada este trabalho. Referente à academia, este estudo visou contribuir para disseminar estudos sobre o desempenho acadêmico dos discentes no curso de Administração. No que diz respeito à contribuição para a instituição onde foi realizada a pesquisa, as autoras tiveram como finalidade proporcionar, aos atores envolvidos no processo de ensino e aprendizagem da área de Administração, uma perspectiva protagonizada pelos próprios discentes sobre a relação entre identificação e desempenho acadêmico. Dessa forma, os achados neste estudo podem servir de subsídios aos diretores, coordenadores e docentes, no planejamento de estratégias pedagógicas consideradas adequadas às necessidades dos estudantes, com base nos relatos apresentados pelos discentes. Somado a isso, foi percebido, através dos dados, a necessidade de estreitar o contato entre instituição e discentes.

Este estudo apresentou limitações quanto a sua abrangência, apenas um curso, uma universidade e uma parcela reduzida de discentes, e quanto a sua natureza transversal. Desta forma, delineamos três sugestões para futuras pesquisas sobre desempenho acadêmico e identificação: a) pesquisas quantitativas que permitam o envolvimento de mais cursos em mais universidades com mais alunos, podendo-se realizar comparações entre os mesmos; b) examinar a relação desempenho academico e identificação de forma longitudinal, acompanhando os discentes em vários momentos de sua graduação, e usando grandes 
amostras para investigar a relação causal entre os dois constructos; e c) incluir variáveis socioeconômicas e culturais dos estudantes e de suas famílias nos estudos e medir suas possíveis correlações.

\section{REFERÊNCIAS}

ALBERT, S.; ASHFORTH, B. E.; DUTTON, J. E. Organizational Identity and Identification: Charting New Waters and Building New Bridges. Academy of Management Review, Briarcliff Manor: Academy of Management, v. 25, n. 1, p.13-17, jan. 2000.

ASHFORTH, B. E.; HARRISON, S. H.; CORLEY, K. G. Identification in Organizations: An Examination of Four Fundamental Questions. Journal of Management, [s.1.], v. 34, n. 3, p. 325-374, 2008.

BARDIN, L. Análise de conteúdo. São Paulo: Edições 70, 2011.

BRANDT, J. Z.i; TEJEDO-ROMERO, F.; ARAUJO, J. F. F. E.. Fatores influenciadores do desempenho acadêmico na graduação em administração pública. Educação e Pesquisa, v. 46, e202500, p. 1-20, 2020.

BORGES, M. S.; MIRANDA, G. J.; FREITAS, S. C..A teoria da autodeterminação aplicada na análise da motivação e do desempenho acadêmico discente do curso de ciências contábeis de uma instituição pública brasileira. Revista Contemporânea de Contabilidade, Florianópolis, v. 14, n. 32, p. 89-107, ago.2017.

BOROS, S.; CURSEU, P. L. To be or not to be...identified. Explorations of students' (dis)identification in a Romanian university. Psihologia Resurselor Umane, [s.l.], v. 10, n.1, p.57-69, 2012.

BRASIL. Ministério da Educação. Instituto Nacional de Estudos e Pesquisas Educacionais Anísio Teixeira. Censo da educação superior 2017. Brasília, DF, 2018. Disponível em: http://portal.mec.gov.br/docman/setembro-2018-pdf/97041-apresentac-a-o-censo-superiorultimo/file. Acesso em: 07 ago. 2019.

BÜCKER, S. et al. Subjective well-being and academic achievement: A metaanalysis. Journal of Research in Personality, v. 74, p. 83-94, 2018.

CORBUCCI, P. R. Desafios da educação superior e desenvolvimento no Brasil. Brasília: Ipea, p. 1-35, jul. 2007. (Texto para discussão, n. 1287).

CRESTANI, R. L. Motivação, inteligência e inteligência emocional e suas relações com o desempenho acadêmico. 2015. Dissertação (Mestrado em Educação) - Universidade do Vale do Sapucaí - UNIVAS, Pouso Alegre, MG, 2015.

CRESWELL,J.W. Projeto de pesquisa: métodos qualitativo, quantitativo e misto. 2.ed. Porto Alegre: Artmed,2007. 
DONOGHUE, S.. Projective Techniques in Consumer Research. Journal of Family Ecology and Consumer Sciences, v.28, p. 57-53, 2000.

DUCKWORTH, A. L. et al. Self-control and academic achievement. Annual Review of Psychology, v. 70, p. 373-399, 2019.

DURÁN SANTOMIL, Pablo et al. Determinantes del rendimiento académico del alumnado de una asignatura de contabilidad : el caso de la USC. Revista de Docencia Universitaria, Valência, v. 14, n. 1, p. 151-178, 2016.

FREITAS, M. E. de. Contexto Social e Imaginário Organizacional Moderno. RAE - Revista de Administração de Empresas, São Paulo, v. 40, n. 2, p. 6-15, 2000.

GIL, A. C. Métodos e técnicas de pesquisa social. 6. ed. São Paulo: Atlas, 2008.

GODOI, C. K.; MATTOS, P. L. C. L. de. Entrevista qualitativa: instrumento de pesquisa e evento dialógico. In: GODOI, C. K.; MELO, R. B. de; SILVA, A. B. da. Pesquisa Qualitativa em Estudos Organizacionais: Paradigmas, Estratégias e Métodos. São Paulo: Saraiva, 2006. p.301-323.

HAVEROTH, J.; SANTOS, C. A. dos; CUNHA, P. R. da. Relação do Afeto Percebido com o Desempenho de Acadêmicos de Ciências Contábeis e Características Individuais. Sociedade, Contabilidade e Gestão, Rio de Janeiro: UFRJ, v. 14, n. 3, p. 1-19, 2019.

JENKINS, R. Social identity. Park Square, Milton Park: Routledge, 2008. 257 p.

KREINER, G. E.; ASHFORTH, B. E. Evidence toward an expanded model of organizational identification. Journal of Organizational Behavior, v. 25. n. 1, p. 1-27, 2004.

LOPES, M. A. S. Análise do desempenho acadêmico dos alunos do curso de ciências contábeis da Universidade Estadual de Montes Claros - UNIMONTES pela forma de ingresso: cotistas e não cotistas. In: XVII Congresso Brasileiro de Custos, Belo Horizonte, 2010. Anais XVII Congresso Brasileiro de Custos, Belo Horizonte, 2010. Disponível em: https://anaiscbc.emnuvens.com.br/anais/article/view/759. Acesso em: 14 ago.2019.

MIRANDA,G.J. Relações entre as qualificações do professor e o desempenho discente nos cursos de graduação em Contabilidade no Brasil. 2011. Tese (Doutorado em Controladoria e Contabilidade: Contabilidade) - Faculdade de Economia, Administração e Contabilidade, Universidade de São Paulo, São Paulo,2011.

MIRANDA, G. J. et al. Determinantes do Desempenho Acadêmico na Área de Negócios. Revista Meta: Avaliação, [s.1.], v. 7, n. 20, p. 175-209, nov. 2015.

MOREIRA, A. M. de A. Fatores institucionais e desempenho acadêmico no ENADE: um estudo sobre os cursos de biologia, engenharia civil, história e pedagogia. 2010. Tese (Doutorado em Educação) - Universidade de Brasília, Brasília, 2010. 
MUNHOZ, A. M. H. Uma análise multidimensional da relação entre inteligência e desempenho acadêmico em universitários ingressantes. 2004. Tese de DoutoradoUniversidade Estadual de Campinas, Campinas, SP, Brasil,2004.

OGUSHI, M. M. P.; BARDAGI, M. P. Reflexões sobre a relação estudante-universidade a partir de uma experiência de atendimento em orientação profissional. Extensio: Revista Eletrônica de Extensão, Florianópolis, v. 12, n. 19, p.33-50, ago. 2015.

OLIVEIRA, C. H. M. de. et al. Busca dos fatores associados à evasão: um estudo de caso no campus universitário da UFC em Crateús. Revista Internacional de Educação Superior, Campinas, v. 5, p. 1-23, 2019.

SANTOS, N. A. Determinantes do desempenho acadêmico dos alunos dos cursos de Ciências Contábeis. 2012.Tese (Doutorado em Controladoria e Contabilidade:

Contabilidade) - Faculdade de Economia, Administração e Contabilidade, Universidade de São Paulo, São Paulo, 2012.

SCHARF, E. R. Paradoxos na identificação organizacional com uma instituição de ensino superior. Revista Gestão Universitária na América Latina - GUAL, Florianópolis, v. 9, n. 2, p. 192-215, maio 2016.

UFV. Universidade Federal de Viçosa. SAPIENS. Sistema de Apoio ao Ensino. Estatísticas, 2020 .

YIN, R. K. Estudo de caso: planejamento e métodos. 2. ed. Porto Alegre: Bookman, 2001. 